\title{
СТРУКТУРНЫЕ ПАРАГЕНЕЗЫ И ТЕКТОНИЧЕСКИЕ НАПРЯЖЕНИЯ ЮЖНОЙ ЧАСТИ ХИБИНСКОГО МАССИВА
}

\author{
Маринин А.В. ${ }^{1}$, Сим Л.А. ${ }^{1}$, Жиров Д.В. ${ }^{2}$ Бондарь И.В. ${ }^{1}$ \\ ${ }^{1}$ Институт физики Земли им. О.Ю. Шмидта РАН, Москва \\ ${ }^{2}$ Геологический институт КНЦ РАН, Апатить
}

Хибинский массив долгие годы представляет уникальную природную лабораторию, к которой проводятся исследования природных тектонических напряжений и вызванных ими структурных деформаций массивов горных пород. Активное проявление горно-динамических воздействий на эксплуатацию месторождений полезных ископаемых обуславливает цели тектонофизических исследований по изучению кинематики систем мелких разрывных нарушений и зеркал скольжения, а также реконструкции палео напряженно-деформированного состояния массива горных пород.

В 2009-2016 годах нами проведены полевые тектонофизические исследования на естественных обнажениях, в подземных и на открытых выработках южной части Хибинского массива. Собранные данные включают более 1000 индикаторов палеонапряжений, в том числе более 500 с кинематической информацией на поверхности разрывных нарушений. Обработка данных полевых замеров геологических стресс-индикаторов проводилась с помощью метода катакластического анализа Ю.Л. Ребецкого [2]. Для реконструкции напряженно-деформированного состояния использовалась программа STRESSgeol, разработанная в лаборатории тектонофизики ИФЗ РАН и использующая алгоритмы вышеуказанного метода. Метод катакластического анализа позволяет определить количественные характеристики реконструируемых локальных стресс-состояний: положение осей главных напряжений/деформаций и коэффициент Лоде-Надаи. При анализе систем тектонической трещиноватости разных кинематических типов с их объединением в устойчивые структурные ассоциации (парагенезы) применен структурно-парагенетический метод Л.М. Расцветаева [1]. Малые разрывные нарушения, зеркала скольжения, отрывы, жилы и другие используемые в данном методе геологические стресс-индикаторы несут информацию о разных этапах деформирования.

В южной части Хибинского массива по данным 2009-2016 гг с помощью метода катакластического анализа были проведены реконструкции палеонапряженного состояния в пределах Кировского рудника, карьеров «Центральный», «Восточный» и «Олений Ручей». Всего удалось произвести расчет для 17 локальных стресс-состояний в пределах южной части Хибинского массива. Такое же количество определений сделано по замерам в окружающих массив образованиях на территории Кольского полуострова. Положение осей главных напряжений в пределах Хибинского массива по данным проведенной реконструкции имеют значительные вариации (рис. 1). Среди преобладающих направлений осей максимального сжатия можно выделить запад - северо-западные (до субширотных) и северо-восточные, а также реже встречающиеся меридиональные ориентировки. Плотностной максимум погружения осей максимального сжатия на стереограмме составляет ВЮВ $110 Đ 25$ (рис. 1). Промежуточные оси часто занимают субвертикальное положение, но довольно много и субгоризонтальных осей, имеющих северо-восточное и субширотное простирание. Оси максимального девиаторного растяжения ориентированы в север - северо-западном направлении или субвертикально. Плотностной максимум погружения осей растяжения на стереограмме составляет ЮЮВ $150 Ð 5$ (рис. 1).

По сравнению с меняющимися по азимуту погружению ориентировками осей главных напряжений более устойчив и информативен тип напряженного состояния, определяемый по положению осей на зенит. По результатам реконструкции установлено, что для рассматриваемого района преобладают обстановки горизонтального сдвига и сжатия, но встречаются и обстановки горизонтального растяжения в сочетании со сдвигом. Таким образом, если в целом по Кольскому полуострову мы видим преобладание обстановки горизонтального сдвига, то в массивах пород южной части Хибин преобладают обстановки горизонтального сдвига и горизонтального сжатия (рис. 2).

В результате проведенных с применением структурно-парагенетического анализа определений получены ориентировки осей максимального сжатия преимущественно северо-восточного и 


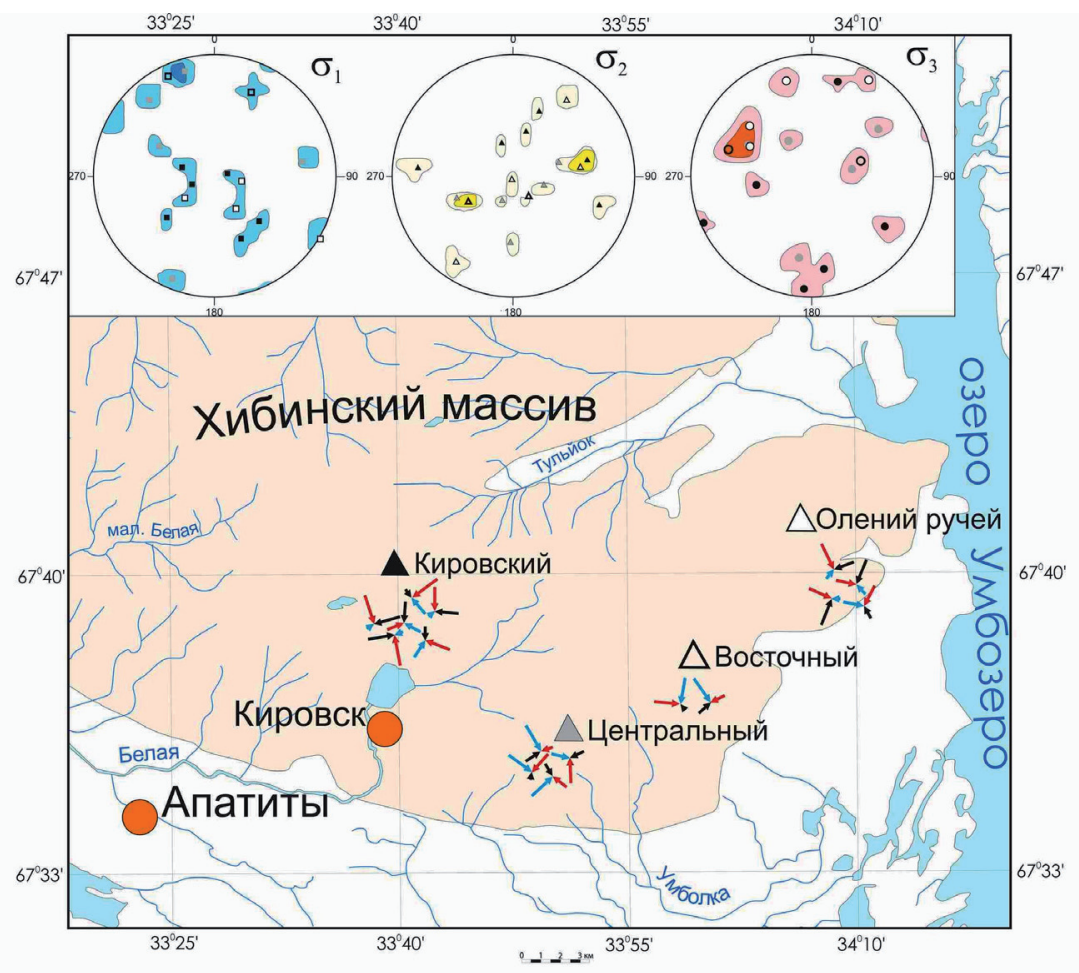

Рис. 1. Ориентировка осей главных напряжений в пределах южной части Хибинского массива.

На схеме показаны оси главных напряжений, ориентированные по погружению: минимальных (девиаторное растяжение, $\left.\sigma_{1}\right)$, промежуточных $\left(\sigma_{2}\right)$ и максимальных $\left(\sigma_{3}\right)$ сжимающих напряжений (синий, черный и красный цвет соответственно). Длина стрелок показывает угол наклона соответствующей оси: короткие - с крутым наклоном, длинные - пологие. В верхней части суммарные диаграммы (стереографическая проекция на верхнюю полусферу) для всего региона, на которых показаны выходы осей главных напряжений и плотностные максимумы их распределения. Заливка значков выходов осей на диаграммах указывает на участок наблюдения.
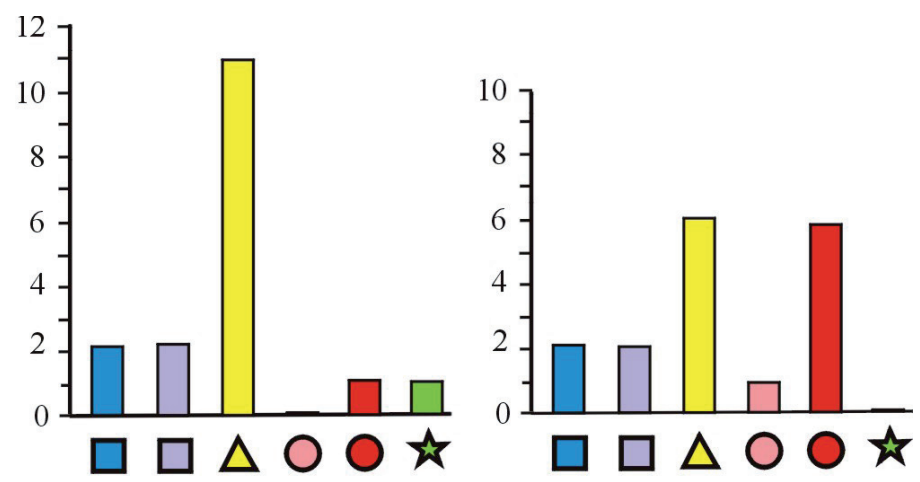

$\square$

\section{$\square 2 \Delta 3 O_{4} O_{5} \star 6$}

Рис. 2. Типы напряженного состояния в пределах Кольского полуострова (слева) и отдельно Хибинского массива (справа) по данным реконструкции геологических индикаторов напряжения. На диаграммах показано количество локальных стресс-состояний с определенным типом напряженного состояния: 1 - горизонтального растяжения, 2 - горизонтального растяжения в сочетании со сдвигом, 3 - горизонтального сдвига, 4 - горизонтального сжатия в сочетании со сдвигом, 5 - горизонтального сжатия, 6 - сдвига в вертикальной плоскости.

северо-западного направлений. Меридиональное и субширотное направления сжатия фиксируются реже. Пример структурного парагенеза с субширотным максимальным сжатием приведен на рис. 3. В парагенезе четко выделяются системы правых сдвигов северо-восточного простирания и левых сдвигов северо-западного простирания, а взбросовые нарушения имеют меридиональное простирание. В правой части (рис. 3) показан расчет ориентировки осей главных напряжений с помощью программы STRESSgeol. В обстановках северо-восточного сжатия преобладают структурные парагенезы субмеридиональных правых сдвигов и субширотных левых сдвигов. При северо-западной ориентации оси сжатия помимо сдвиговых парагенезов существенную роль играют взбросовонадвиговые системы северо-восточного простирания. Данные системы образуют характерный максимум с простиранием по азимуту СВ $30^{\circ}$, который преобладает среди всех кинематических типов 


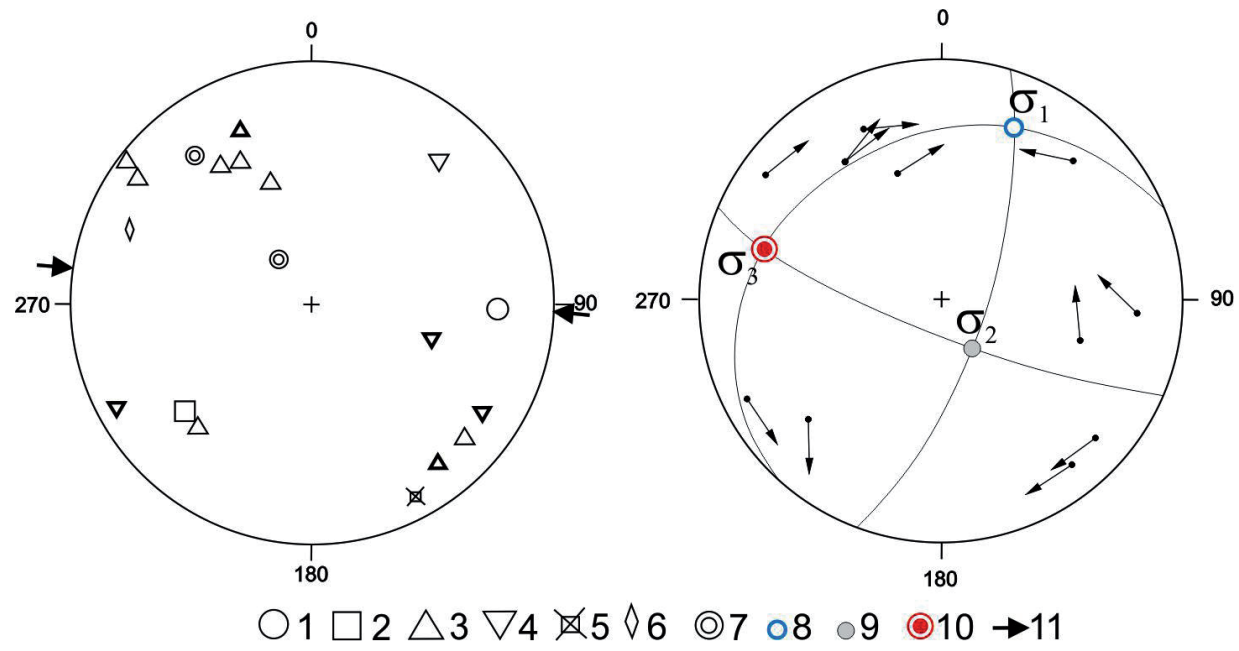

Рис. 3. Круговые диаграммы (стереографическая проекция на верхнюю полусферу), показывающие полюса плоскостей тектонических трещин разного кинематического типа и положение осей главных напряжений, определенных методом катакластического анализа в точке наблюдения № 10530 (рудник «Восточный») в южной части Хибинского массива: 1-7 - полюса тектонических трещин с преимущественным типом перемещений: 1 - взбросы, 2 - сбросы, 3 - правые сдвиги, 4 - левые сдвиги, 5 - отрывы, 6 - сдвиги, 7 - зоны дробления; 8-10 - оси главных нормальных напряжений: 8 - минимальных, 9 - промежуточных, 10 - максимальных, 11 - ориентировка оси максимального сжатия по данным структурно-парагенетического анализа тектонической трещиноватости. Толщина линий значков (1-4) указывает на степень достоверности определения кинематики смещения: с толстыми - хорошая, с тонкими - предполагаемая.

зеркал скольжения и малых разрывов. Отрывные структуры в рассматриваемом районе фиксируются значительно реже и не образуют значимых максимумов. Северо-западное направление сжатия для Хибинского массива ранее реконструировано кинематическим методом [3].

\section{Выводы}

В пределах Хибинского массива обстановки горизонтального сжатия фиксируются при реконструкции палеонапряжений разными методами. Структурно это выражается в наличии многочисленных разрывных зон с преобладанием надвиговой и взбросовой кинематики. Роль обстановок горизонтального сжатия существенно выше в пределах массива и сопоставима с обстановками горизонтального сдвига, которые резко преобладают на остальной территории Кольского полуострова.

По данным проведенной реконструкции наиболее проявлено запад - северо-западное направление максимального сжатия, которое обуславливает и наиболее проявленную систему взбросовых зеркал скольжения и мелких разрывов север -северо-восточного простирания. Проведенные реконструкции ориентировок осей главных напряжений показывают большую вариабельность по сравнению с определениями in-situ, что на наш взгляд может быть объяснено присутствием древних деформационных структур, которые не были переработаны или переориентированы в соответствии с современным напряженно-деформированным состоянием. Разнообразие ориентации осей главных напряжений и типов напряженного состояния может также свидетельствовать о наличие внутренних источников тектонических напряжений. Для более тщательного анализа палеонапряжений и систем тектонической трещиноватости Хибинского массива необходимо получение полевой тектонофизической информации по другим частям массива.

\section{Литература}

1. Расцветаев Л.М. Парагенетический метод структурного анализа дизъюнктивных тектонических нарушений. Проблемы структурной геологии и физики тектонических процессов. М.: ГИН АН СССР, 1987. Ч. 2. С. 173-235.

2. Ребецкий Ю.Л. Тектонические напряжения и прочность горных массивов. М.: Изд. Наука. 2007. 406 с.

3. Сим Л.А., Жиров Д.В., Маринин А.В. Реконструкция напряженно-деформированного состояния восточной части Балтийского щита // Геодинамика и тектонофизика. 2011. Т. 2. № 3. С. 219-243. 